\title{
Silymarin's Defensive Role Against Hepatotoxicity induced By Amiodarone In Albino Rats
}

\author{
El Efecto Defensivo de Silimarin Contra la Hepatotoxicidad \\ Inducida por Amiodarona en Ratas Albinas
}

\author{
Refaat A. Eid ${ }^{1}$; Mohamed Samir Ahmed Zaki ${ }^{2,3}$; Mubarak Al-Shraim ${ }^{1}$; \\ Muhammad Alaa Eldeen ${ }^{4}$; Ehab El Sayed Massoud ${ }^{5}$; Ayed A. Shati ${ }^{6}$; Samaa S. Kamar ${ }^{7}$ \& Mohamed A. Haidara ${ }^{8}$
}

EID, R. A.; ZAKI, M. S. A.; AL-SHRAIM, M.; ELDEEN, M. A.; MASSOUD, E. E. S.; SHATI, A. A.; KAMAR, S. S. \& HAIDARA,

M. A. Silymarin's defensive role against hepatotoxicity induced by amiodaron ein albino rats. Int. J. Morphol., 39(2):407-415, 2021.

SUMMARY: Amiodarone (AMD), an orally powerful antidysrhythmic medication that has caused hepatotoxicity on long-term administration, is commonly used across the world. Silymarin ameliorative effects (SLM); this research elucidated the magnitude of the damage to the liver tissue in AMD. We divided 24 albino rats evenly into four groups given daily doses by gastric tube for eight weeks as follows; the $1^{\text {st }}$ group acted as a control group; the $2^{\text {nd }}$ group received SLM; the $3^{\text {rd }}$ group received AMD; and the $4^{\text {th }}$ group received AMD parallel to SLM. Liver tissues prepared for light, electron microscopic and serum samples screened for biomarkers (I)liver injury enzymes, alanine aminotransferase (ALT) and aspartate aminotransferase (AST); (II) oxidative and antioxidant stress, malondialdehyde (MDA) and superoxide dismutase ( SOD); and (III) inflammatory markers, tumor necrosis factor-alpha (TNF- $\alpha$ ) and interleukin-6 ( IL-6). The findings showed that AMD caused hepatic histological changes that included congestion of the blood vessels, leucocytic infiltration and cytoplasmic vacuolation. Ultrastructural degeneration of the mitochondria, endoplasmic reticulum swelling, nuclear pyknosis and increased fat droplets and lysosomes were observed. The biochemical findings showed an increase in the AMD group's ALT and AST activities. The group of rats treated with AMD and SLM, increased the improvements in histology and ultrastructure, while the ALT and AST levels were reduced. Our findings collectively agreed that SLM has a protective impact on AMD hepatotoxicity which can be due to its antioxidant properties.

KEY WORDS: Amiodarone; Silymarin; Liver; Biochemical enzymes; Histology, Ultrastructure; Statistical analysis.

\section{INTRODUCTION}

Amiodarone (AMD) is a widely prescribed antiarrhythmic drug on a broad spectrum. It is a derivative of strongly lipophilic iodinated benzofuran (Joukar et al., 2014). AMD has significant adverse effects on many organs including the cornea, liver, lung, neuromuscular system, skin and thyroid that often restrict its use (Nasri et al., 2016). A significant feature of amiodarone is its high solubility in lipids. It accumulates mainly in adipose tissue and heavily perfused organs such as liver, lungs, and spleen (LafuenteLafuente et al., 2009).

AMD-mediated lipid peroxidation (LPO) is an initiating occurrence of pulmonary fibrosis that is caused by its. When free radicals act on polyunsaturated fatty acids and cholesterol, lipid peroxidation occurs. The LPO begins with a free radical giving an unpaired electron to a methylene carbon in a polyunsaturated fatty acid, then reacts with molecular oxygen to form a peroxyl radical. This peroxyl radical react with adjacent fatty acid side chains plus another peroxyl radical, attack membrane proteins, or abstract hydrogen atoms resulting in the creation of a subsequent peroxyl radical.In this way, the chain reaction of LPO is continued and can result in damage to the membrane, inhibition of the enzymes, release of lysosomal enzymes and cross-linking of protein-proteins, which can lead to cell death (Nicolescu et al., 2007).

\footnotetext{
${ }^{1}$ Pathology Department, College of Medicine, King Khalid University, Abha 61421, Saudi Arabia.

${ }^{2}$ Anatomy Department, College of Medicine, King Khalid University, Abha 61421, Saudi Arabia.

${ }^{3}$ Histology Department, College of Medicine, Zagazig University, Egypt.

${ }^{4}$ Biology Department, Physiology Section, Faculty of Science, Zagazig University, Egypt.

${ }^{5}$ Department of Biology, Faculty of Sciences and Arts in DahranAljanoub,King Khalid University, P.O. Box 28, 61954, DahranAljanoub, Saudi Arabia.

${ }^{6}$ Department of Child Health, College of Medicine, King Khalid University, Abha, Saudi Arabia.

${ }^{7}$ Department of Medical Histology, Kasr al-Aini Faculty of Medicine, Cairo University, Cairo, Egypt.

${ }^{8}$ Physiology Department, Kasr al-Aini Faculty of Medicine, Cairo University, Cairo, Egypt.
} 
AMD and its metabolites accumulate in hepatocyte lysosomes and induce phospholipase inhibition A1 and A2, which prevents the removal of lysosomal lipids and results in phospholipidosis (Martin 2nd et al., 1989). This pathway leads to steatohepatitis, and eventually to permanent cirrhosis of the liver. The development of lamellar lysosomal inclusion bodies visualized by electron microscopy is a typical discovery of hepatotoxicity caused by amiodarone (Lewis et al., 1990).

The flavonoid silymarin (SLM) is a substance whose hepatoprotective properties are known. The action mechanism remains poorly known. The evidence in the literature indicate that silymarin acts as an antioxidant, scavenger and regulator of glutathione intracellular content; stimulates liver regeneration; and as an inhibitor of stellate hepatocyte transformation into myofibroblasts (AbdelMoneim et al., 2015). The main mechanism ensuring hepatoprotection appears to be free radical scavenging, affecting the enzyme systems associated with glutathione and superoxide dismutase. The anti-inflammatory and anticarcinogenic effects of toxins, ethanol and psychotropic drugs have also been reported in hepatotoxicity (Mata-Santos et al., 2014). SLM is well tolerated and successful in the treatment of many liver disorders with degenerative necrosis and functional disability, and offers hepatoprotection against galactosamine, thioacetamide, halothane and carbon tetrachloride poisoning (Shaker et al., 2011). This also protects hepatocytes against ischemia, radiation, iron toxicity, and iron overload and viral hepatitis.

This research aimed to assess the possible protective effect of SLM against AMD-induced hepatotoxicity through histological, histochemical, ultrastructural, biochemical, and statistical analysis.

\section{MATERIAL AND METHOD}

Experimental animals. In this study we used twenty-four white male albino rats from the animal house of King Khalid University of Saudi Arabia. Animals weighing (140-180 gm) housed at room temperature $\left(25 \pm 5^{\circ} \mathrm{C}\right)$ in stainless steel cages and obtained complete diet pellets and water ad-libitum (Gonder \& Laber, 2007). We kept animals under observation for approximately two weeks before the start of the experiment to rule out any intercurrent infections.In the present research, we adopted the European Community Directive (86/609 / the $8^{\text {th }}$ edition of the EEC) and National animal care guidelines established in conjunction with laboratory animal care and use guidelines (NIH Guidelines).

Chemicals and tr eatment. Amiodarone (amiodarone hydrochloride) was imported under the license of Sanofi Synthel abo from Global Napi business for pharmaceuticals products. The tablets with the brand name Cordarone contained $200 \mathrm{mg}$ per tablet.

Silymarin: A product of Global Pharmaceutical Industries, Egypt; formulated as a suspension with a final concentration of $15 \mathrm{mg} / \mathrm{ml}$ in aqueous solution of carboxy methyl cellulose (CMC) 0.5 per cent.

Animal grouping. Each of AMD and SLM were dissolvedin distilled water and was given by gastric intubation daily for eight weeks (time of the experiment). The animals disaggregated into four groups:

1. The 1st group served as control group under the same laboratory conditions, and was given $1 \mathrm{ml}$ of corn oil/day.

2 . The $2 \mathrm{nd}$ group received $(140 \mathrm{mg} / \mathrm{kg} /$ day $)$ of silymarin.

3 . The $3 \mathrm{rd}$ group received $(30 \mathrm{mg} / \mathrm{kg}$ body weight/day ofamiodarone.

4. The 4 th groupreceived $(30 \mathrm{mg} / \mathrm{kg} / \mathrm{day})$ of amiodarone parallel with silymarin $(140 \mathrm{mg} / \mathrm{kg} /$ day $)$ at the same time.

8 weeks after treatment the animals were sacrificed. We collected blood and extracted serum to test liver enzyme activity. Liver for the histological and ultra-structural studies was freshly isolated, cleaned, and used.

Biochemical study: Alanine aminotransferase (ALT) activity in serum was followed Schumann \& Klauke method (2003). Aspartate aminotransferase (AST) activity in serum was followed Schumann \& Klauke (2003) by using reagent kits purchased from Company of Human (Germany). The superoxide dismutase (SOD), activity was assessed according to Mylroie et al. (1986) and malondialdehyde (MDA) assessed according to Ohkawa et al. (1979).

Determination of serum levels of TNF- $\alpha$, and IL-6. Animals were sacrificed after 8 weeks and tissue levels of TNF- $\alpha$ were determined, and IL- 6 were assessed using ELISA kits as instructed by the manufacturer.

Preparation of paraffin sections: At the end of the 8th week of treatment, the animals were anesthetized for histologic preparations with mild diethyl ether, and dissected to remove the liver. The liver was divided into small parts and then fixed in 10 per cent neutral formalin for $24 \mathrm{~h}$. The liver specimens were washed to remove the excess fixative and then dehydrated to the ascending grades of ethyl alcohol, after which they were transparent in two changes of xylene.Then, the specimens were impregnated with three paraplast plus modifications at $60^{\circ} \mathrm{C}$. Sections prepared $(4-5 \mu \mathrm{m})$ thick with a microtome, then stained with hematoxylin and eosin (Castro \& Camargo, 1951) for histological studies or with Masson's trichrome staining (Drury et al., 1976) and examined under light microscope for histological analysis according to Bancroft \& Gamble (2002). 
Ultrastructural preparations: Cut specimens from the liver of all animal groups into small pieces, each piece measured about $1 \mathrm{~mm}^{3}$, then fixed immediately at $4^{\circ} \mathrm{C}$ for $18-24 \mathrm{~h}$ in freshly $3 \%$ glutaraldehyde-formaldehyde. Specimens were washed in phosphate buffer ( $\mathrm{pH} 7.4)$, and post fixed for one hour at $4^{\circ} \mathrm{C}$ in isotonic $1 \%$ osmium tetroxide (Mercer \& Birbeck, 1966). Prepared sections for electron microscopic evaluation followed the method of Bozzola \& Russell (1999). Stained semi-thin sections with toluidine blue to detect the region of interest, then used the ultra-microtome glass knives to prepare ultrathin parts. Stained with uranyl acetate and lead citrate, then tested with an electron microscope for transmission by Joel JEM-1011, operated at $80 \mathrm{kv}$ in faculty of Medicine, KKU (Eid et al., 2020).
Statistical analysis: The data for each group were expressed as mean $(\mathrm{M}) \pm$ standard error (SE), test for significant difference between different groups use One-way ANOVA with post-hoc Duncan tests, if $\mathrm{P}<0.001$ the differences were considered statistically significant.IBM SPSS Statistics (Version 20, New York, USA) were used to perform analyses (Dawson \& Trapp, 2001).

\section{RESULTS}

Biochemical study: SLM protects the oxidative stress and antioxidant biomarkers in rats from AMD-induced modulation. Liver serum levels of MDA (Fig. 1A) and SOD (Fig. 1B) were measured on completion of the experiment in different groups of rats used in this study; Control, SLM, AMD and SLM+AMD groups.

SLM protects against AMD-induced modulation of oxidative stress and antioxidant biomarkers in rats. Liver serum levels of MDA (Fig. 1C) and SOD (Fig. 1D) were measured on completion of the experiment in different groups of rats used in this study; Control, SLM, AMD and SLM+AMD groups.

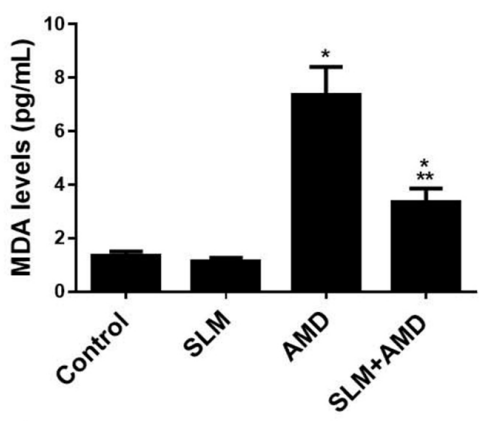

C

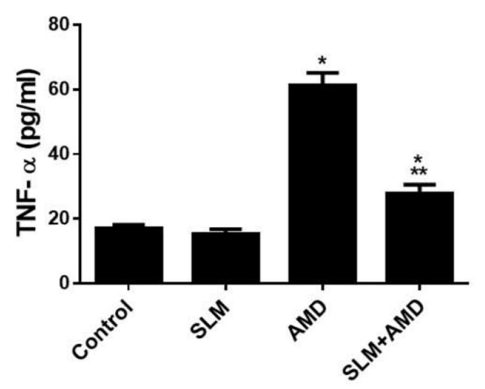

E

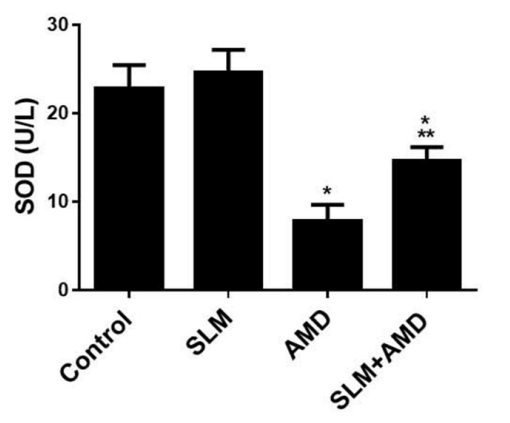

D

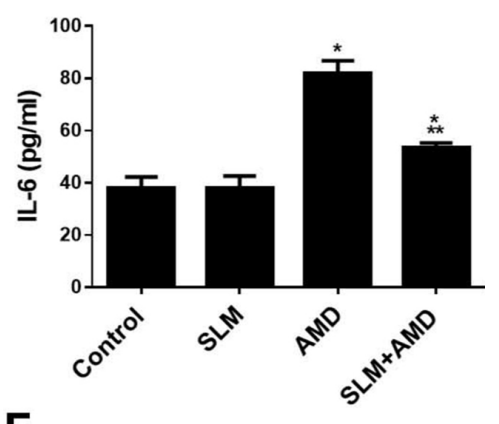

Fig. 1. Biochemical Results of the livers of control and treated rats showing:

A\&B:SLM protects against AMD-induced modulation of oxidative stress and antioxidant biomarkers in rats. Liver homogenates levels of MDA (A) and SOD (B) were measured; Control, SLM, AMD and SLM+AMD groups. Results represent the mean $( \pm S D) ; n=6$ for each group. Experiments were performed in triplicate. ${ }^{*} \mathrm{p}<0.0001$ versus control, $* * * p<0.001$ versus AMD.

C\&D:SLM protects against AMD-induced modulation of oxidative stress and antioxidant biomarkers in rats. Liver homogenates levels of MDA (A) and SOD (B) were measured; Control, SLM, AMD and SLM+AMD groups. Results represent the mean $( \pm \mathrm{SD}) ; \mathrm{n}=6$ for each group. Experiments were performed in triplicate. ${ }^{*} \mathrm{p}<0.0001$ versus control, $* * * \mathrm{p}<0.001$ versus AMD.

E\&F:SLM inhibits AMD-induced inflammatory biomarkers in rats. Liver homogenates levels of TNF- $\alpha$ (A) and IL-6 (B) were measured; Control group, SLM group, and SLM+AMD group. Results represent the mean $( \pm S D)$; $n=6$ for each group. Experiments were performed in triplicate. ${ }^{*} \mathrm{p}<0.0001$ versus control, $* * * \mathrm{p}<0.0001$ versus AMD. 
SLM inhibits AMD-induced inflammatory biomarkers in rats. Liver serum levels of TNF- $\alpha$ (Fig. 1E) and IL-6 (Fig. 1F) were measured on completion of the experiment in different groups of rats used in this study; Control group, SLM group, and SLM+AMD group.

Light microscopic observations: The liver sections of the control rats displayed normal architecture without disruption in the central vein and without changes in the architecture of the sinusoids and hepatocytes (Fig. 2A). For SLM treatments the same histology structure was seen almost (Fig. 2B). In the toxic AMD group, the parts of the liver showed swollen and degenerated hepatocytes, associated sinusoids in the blood and accumulation of inflammatory cells surrounding the central vein (Fig. 2C). The liver portion showed improvement of hepatocytes and sinusoids in the blood with few inflammatory cells in the toxic AMD group treated with SLM (Fig. 2D).

Ultrastructural observations: Throughout the current study, the control hepatic cells and SLM treated rats showed large rounded nucleus and surrounded by nuclear envelope nucleolus with typical euchromatin and heterochromatin distribution. Profiles of rough endoplasmic reticulum observed especially around the nuclear envelope and in between the mitochondria in of
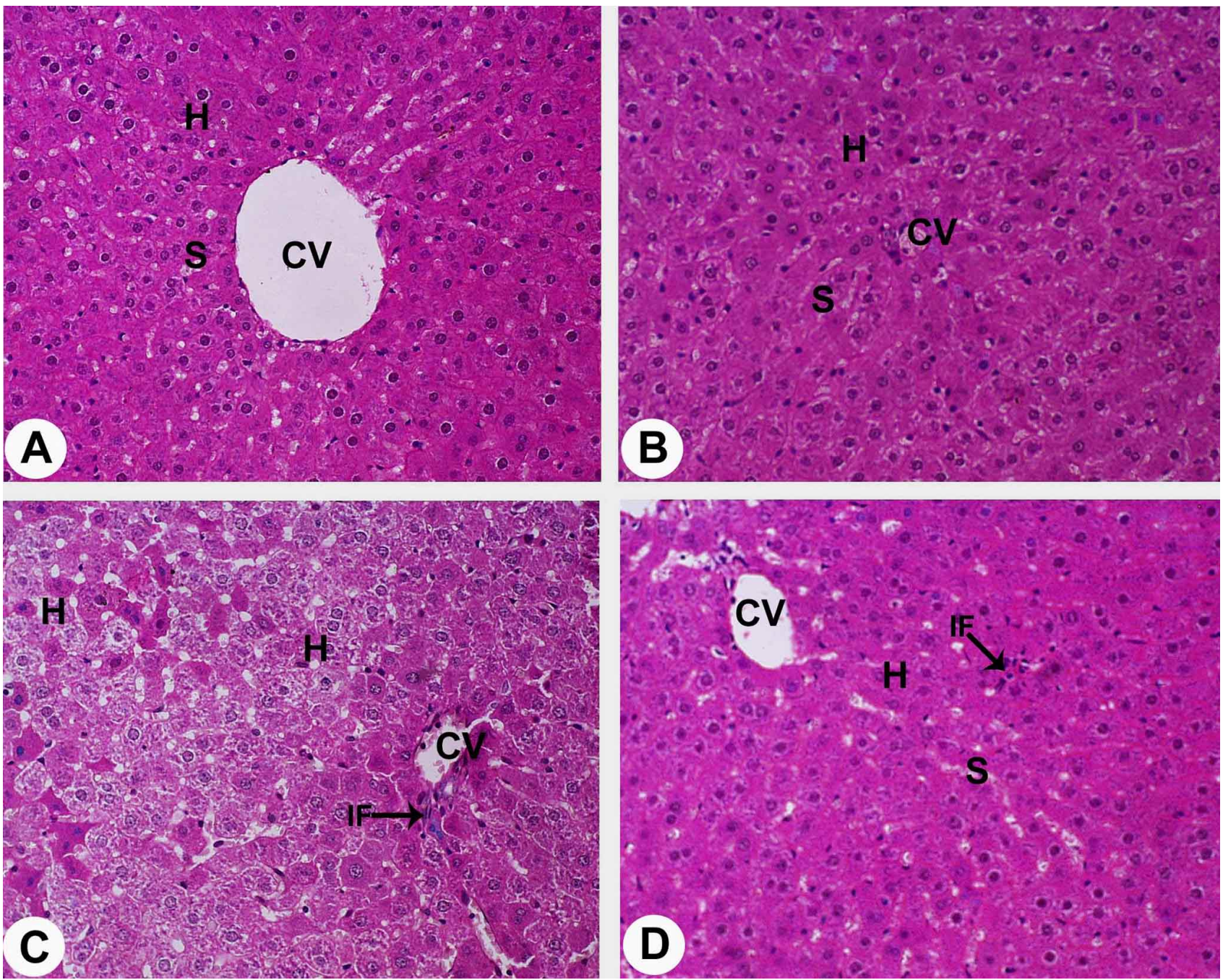

Fig. 2. Photomicrographs of the livers of control and AMD treated rats stained by H\&E showing:

A. Normal hepatocytes $(\mathrm{H})$ with rounded nuclei and blood sinusoids $(\mathrm{H})$ around central vein $(\mathrm{CV})$ of control rats. (X 400).

B. Intact hepatocytes $(\mathrm{H})$ with rounded nuclei and blood sinusoids $(\mathrm{S})$ around central vein $(\mathrm{CV})$ of silymarin -treated rats. (X 400).

C. Swollen and degenerated hepatocytes (H) and damaged blood sinusoids (S). Note accumulation of inflammatory cells (IF) around central vein (CV) of amiodarone - treated rats. (X 400).

D. Improvement of both hepatocytes $(\mathrm{H})$ and blood sinusoids $(\mathrm{S})$ are observed around the central vein $(\mathrm{CV})$ of amiodarone plus silymarin -treated rats. Few inflammatory cells (IF) are seen as partial changes. (X 400). 
EID, R. A.;ZAKI, M. S. A.; AL-SHRAIM, $\odot$ M.; ELDEEN, M. A.; MASSOUD, E. E. S.; SHATI, A. A.; KAMAR, S. S. \& HAIDARA, M. A. Silymarin's defensive role against hepatotoxicity induced by amiodaron ein albino rats. Int. J. Morphol., 39(2):407-415, 2021

hepatocytes cytoplasm. The mitochondria are numerous rounded and elongated profiles with membranous cristae and electron dense matrix (Figs. 3A-D).

In contrast, AMD bearing rat liver tissue showed ultrastructural changes including hepatocyte apoptosis with pyknotic nucleus and swollen pleomorphic mitochondria.In the sinusoidal blood thickened desmosomes and cytoplasmic inclusion were also found. The degenerated hepatocytes displayed abnormal and atrophied nuclei with condensed masses of chromatin on a distorted envelope (Figs. 4A-B). In addition, dilated rough endoplasmic reticulum was also observed and mitochondria impaired. Accumulation of lipid droplets within blood sinusoid and degenerated hepatocytes with cytoplasmic fatty-like materials and vacuoles were also observed. Increased levels of inflammatory cells and deposition of collagen fibers between degenerated hepatocytes and blood sinusoids had also been shown (Figs. 4C-D).
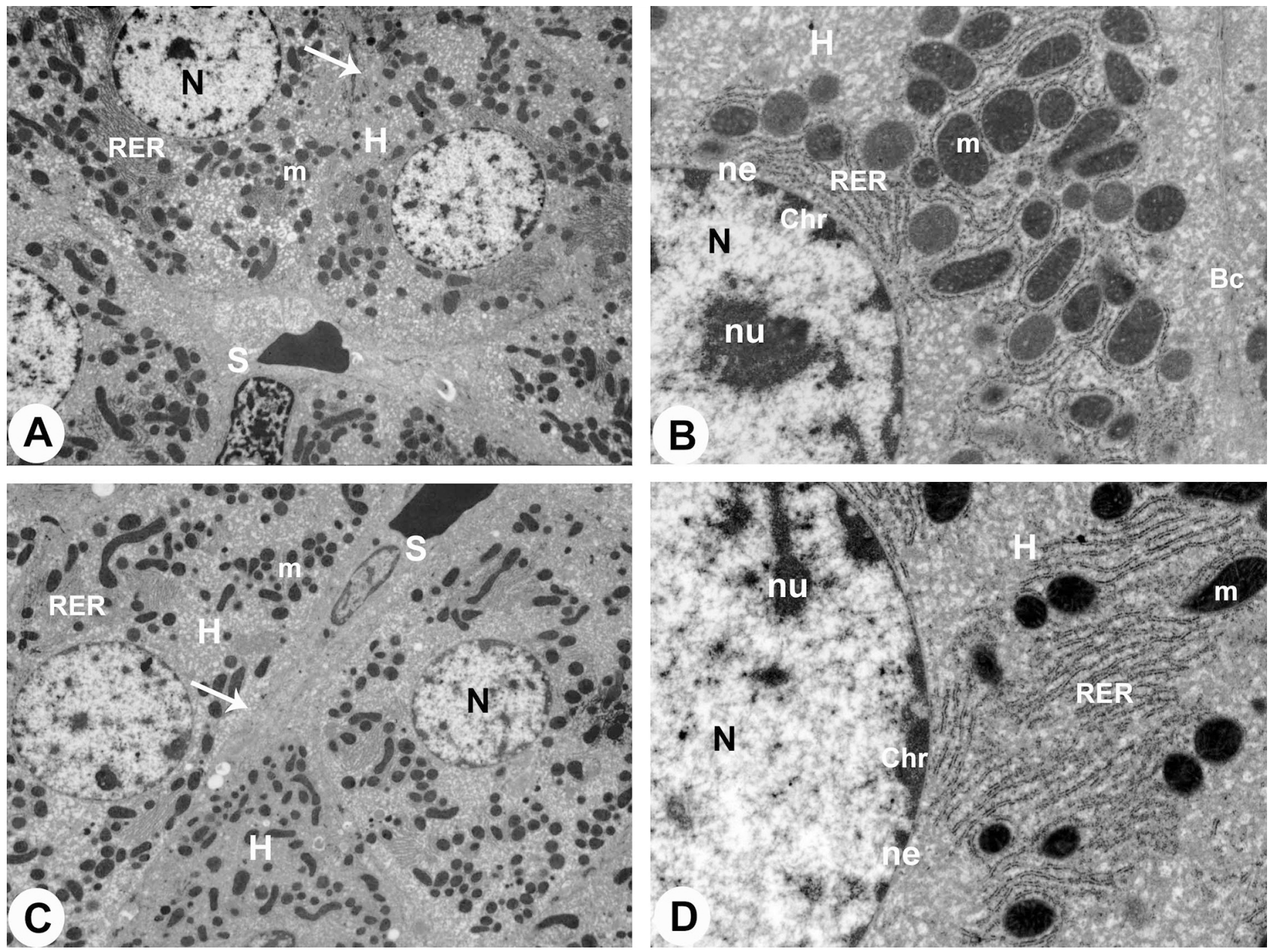

Fig. 3. Transmission electron micrographs (TEM) of the livers of control and SLMtreated rats stained by uranyl acetate \& lead citrate showing:

A. Normal hepatocyte $(\mathrm{H})$ involved nucleus $(\mathrm{N})$, rough endoplasmic reticulum (RER) and mitochondria (m) of control rats. Intercellular plasma membrane (arrow) and blood sinusoids (S) are also seen. (X 5000).

B. Higher magnification of normal hepatocyte $(\mathrm{H})$ showing nucleus $(\mathrm{N})$ which surrounded by nuclear envelope (ne) and contained chromatin masses (Chr) and nucleolus (nu). Rough endoplasmic reticulum (RER), mitochondria (m) and bile canaliculus (Bc) of control rats are also seen. (X 20000).

C. Intact hepatocyte $(\mathrm{H})$ involved nucleus $(\mathrm{N})$, rough endoplasmic reticulum (RER) and mitochondria $(\mathrm{m})$ of silymarin -treated rats. Intercellular plasma membrane (arrow) and blood sinusoids (S) are also seen. (X 5000).

D. Higher magnification of normal hepatocyte $(\mathrm{H})$ showing nucleus $(\mathrm{N})$ which surrounded by nuclear envelope (ne) and contained chromatin masses (Chr) and nucleolus (nu). Rough endoplasmic reticulum (RER) and mitochondria (m) of silymarin -treated rats are also seen. (X 20000). 

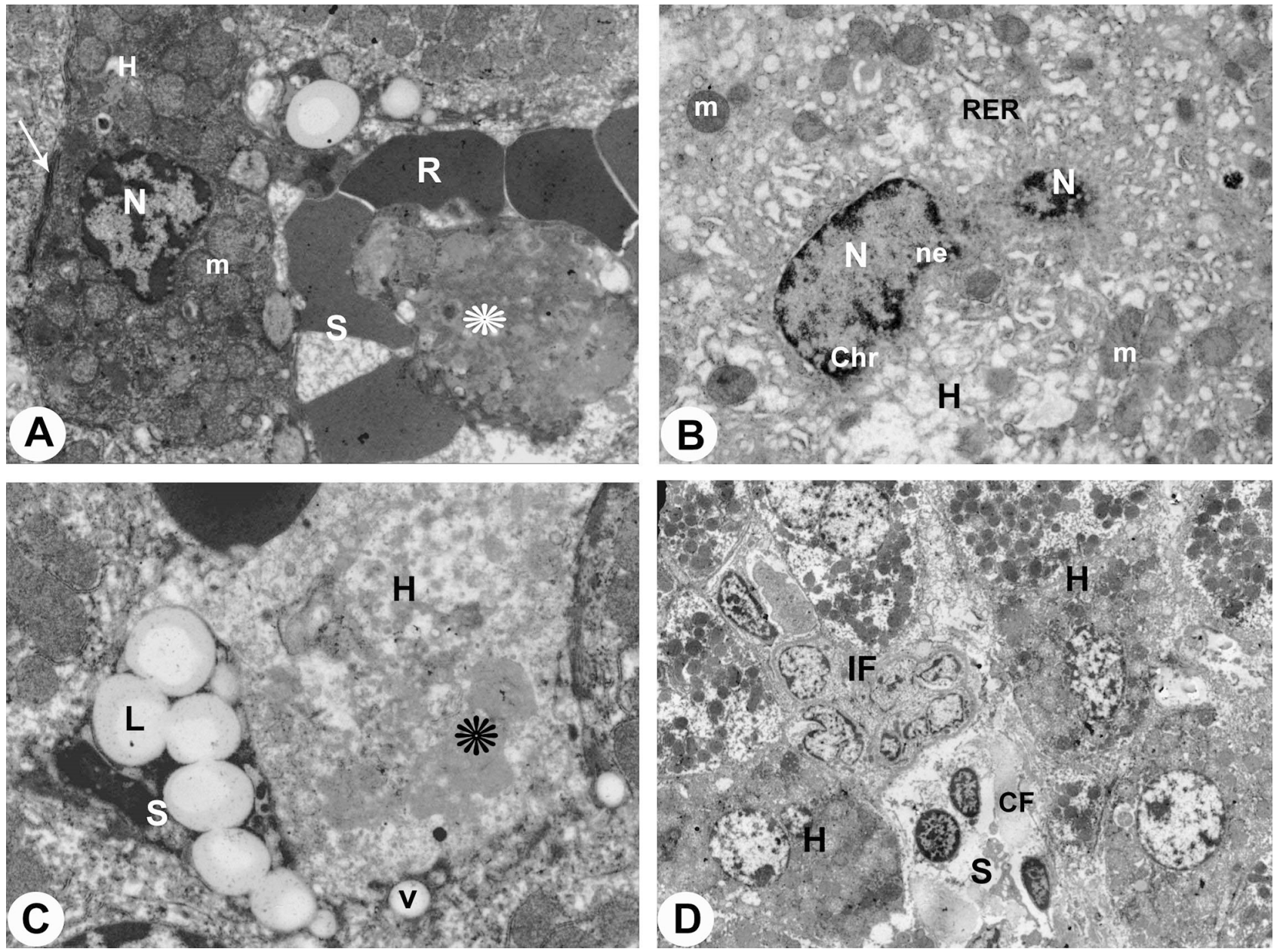

Fig. 4. Transmission electron micrographs (TEM) of the livers of AMD treated rats stained by uranyl acetate \& lead citrate showing:

A. Apoptotic and necrotic hepatocytes $(\mathrm{H})$ with pyknotic nucleus $(\mathrm{N})$ and swollen pleomorphic mitochondria $(\mathrm{m})$. Thickened desmosome (arrow) and cytoplasmic inclusion (asterisk) in blood sinusoid (S) are also seen. R, erythrocytes. (X 5000).

B. Degenerated hepatocytes $(\mathrm{H})$ showing irregular-shaped and atrophied nuclei $(\mathrm{N})$ with condensed chromatin masses (Chr) on irregular envelope (ne). Dilated rough endoplasmic reticulum (RER) and damaged mitochondria (m) are also observed. (X 5000).

C. Increase amounts of lipid droplets (L) within blood sinusoid (S) and degenerated hepatocytes $(\mathrm{H})$ with cytoplasmic fatty-like materials (asterisk) and vacuoles (V) are also seen. (X 20000).

D. Increase amounts of inflammatory cells (IF) and bundles of collagen fibers (CF) are demonstrated in between degenerated hepatocytes (H) and blood sinusoids (S). (X 5000).

But AMD's liver tissue parallel with SLM showed remarkable improvements. The hepatic cell nuclei were more or less identical to control nuclei. In the cytoplasm of these cells the mitochondria and rough endoplasmic reticulum were prominent in a balanced appearance and the lipid droplets were mostly disappeared (Figs. 5A-B).

\section{DISCUSSION}

Results obtained in this study revealed that AMD induces histological and ultrastructural alterations in rat hepatic tissue. In the toxic AMD group, hepatic cell necrosis was reported along by the liver sections; some of 

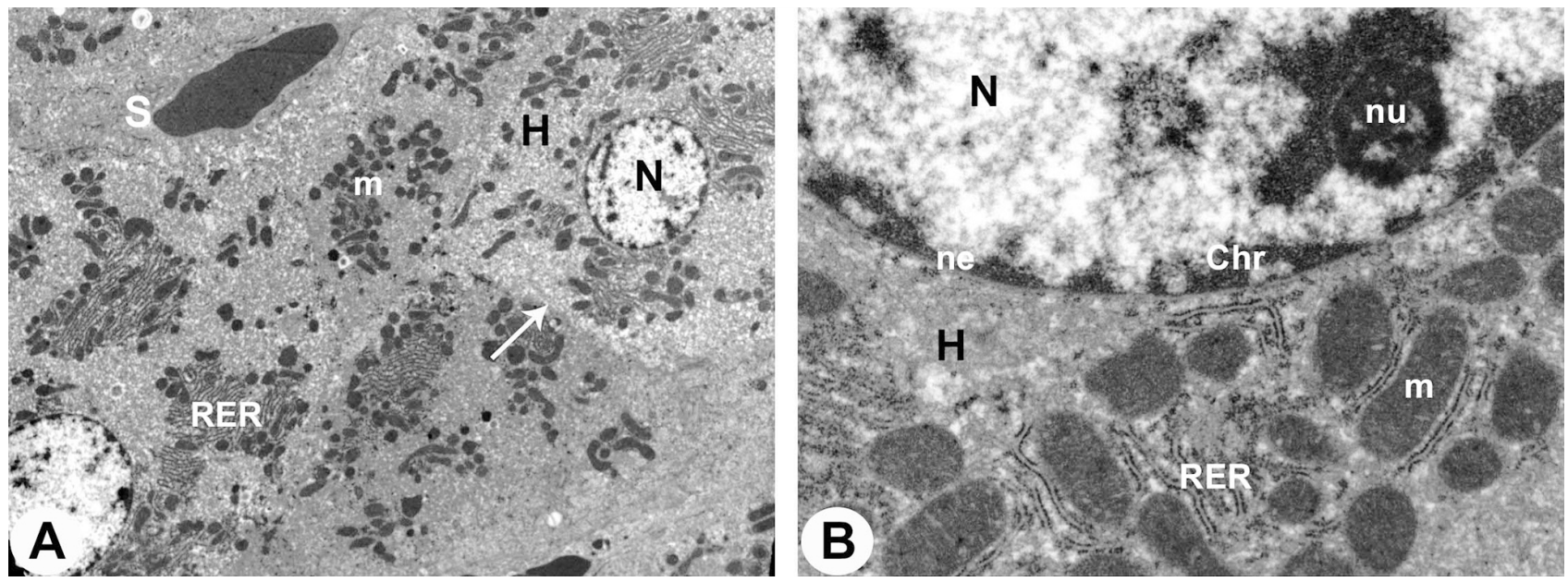

Fig. 5. Transmission electron micrographs (TEM) of the livers of AMD plus SLM treated rats stained by uranyl acetate \& lead citrate showing:

A. Improvement in hepatocyte $(\mathrm{H})$ involved nucleus $(\mathrm{N})$, rough endoplasmic reticulum $(\mathrm{RER})$ and mitochondria $(\mathrm{m})$ of amiodarone plus silymarin -treated rats. Intercellular plasma membrane (arrow) and blood sinusoids (S) are also seen. (X 5000).

B. Higher magnification of intact hepatocyte $(\mathrm{H})$ showing nucleus $(\mathrm{N})$ which surrounded by nuclear envelope (ne) and contained chromatin masses (Chr) and nucleolus (nu). Rough endoplasmic reticulum (RER) and mitochondria (m) of amiodarone plus silymarin -treated rats are also seen. (X 20000).

the hepatocytes were vacuolated with severe damage associated with central vein. Ultrastructural changes were observed in this group including hepatocyte apoptosis with pyknotic nucleus, swollen pleomorphic mitochondria, thickened desmosome and cytoplasmic inclusion in the blood sinusoid. The severity of the amiodarone side effects is related to overall exposure to total drug exposure. The liver toxicity is usually intermittent and will improve after the dose has been decreased or released. Aspartate aminotransferase (AST) and alanine aminotransferase (ALT) are well known to increase in liver damage caused by amiodarone (Fonseca et al., 2015).

SLM's hepatoprotective and antioxidant activity was due to its ability to remove free radicals that are formed during the hepatic metabolism of toxic substances by inhibiting the cycle of cyclooxygenase and leukothrines (Vargas-Mendoza et al., 2014). Furthermore, this flavonoid has a phenolic structure that enables the electronic donation of free radicals and reactive oxygen species (ROS) to stabilize them and prevent lipid peroxidation through association with intracellular glutathione (Karimi et al., 2011; Vargas-Mendoza et al., 2014). In addition, it has been documented that SLM has anti-proliferative, anti-fibrotic, anti-apoptotic, antiviral and immunomodulatory properties (Tsai et al., 2008; Sasu et al., 2015) and has been shown to inhibit tumor necrosis factor-alpha expression (TNF- $\alpha$ ) (Ahmad et al., 2013).
However, AMD's liver tissue parallel to SLM exhibits remarkable hepatocyte improvement with their nuclei and organelles. SLM administration has alleviated the aforementioned hepatocyte injuries, indicating that silymarin functions as a free radical scavenger though its liver defense effects against lipid peroxidation, which has been demonstrated in other studies (Vargas Mendoza et al., 2014), by enhancing antioxidant status.

Biological therapy for inhibiting TNF- $\alpha$, a proinflammatory cytokine, has become a commonly used, safe and efficient treatment for patients with inflammatory bowel disease (Ford et al., 2011).

IL-6 has long been recognized as an essential proinflammatory cytokine that has many inflammatory disorders associated with its expression. Serum IL-6 levels rise rapidly after infection or inflammation of the organ and are therefore used as a diagnostic marker in clinical practice to diagnose inflammatory conditions, in particular sepsis (Jekarl et al., 2013). For patients with acute and chronic liver disorders, serum and intrahepatic levels of IL-6 are also greatly increased (Streetz et al., 2003).

In our experiment, AMD plus SLM substantially inhibits liver damage and effectively inhibits the modulation of MDA, SOD,TNF- $\alpha$ and IL- 6 in rat hepatotoxicity induced by AMD. Whereas the 
administration of SLM with AMD induced inhibition of liver injury biomarkers, ALT and no effect on the levels of ALT in cultivated hepatocytes prepared from these animals (Wojnarová et al., 2015).

In the current experiment, either silymarin defense or treatment showed a significant decrease in TNF- $\alpha$ and MDA levelsand a significant increase of SOD activity in liver tissue compared to the untreated group.

\section{CONCLUSION}

The findings of this investigation suggest that SLM offers hepatoprotection and cellular defense against AMDinduced hepatotoxicity. SLM decreased the impact caused by ALT, AST AMD. However, hepatocyte histological and morphological changes showed that SLM has antioxidant properties.

\section{FUNDING}

This research was fully funded by Deanship of Scientific Research at King Khalid University, Abha, Kingdom of Saudi Arabia (Grant No. G.R.P- 57-41).

\section{ACKNOWLEDGEMENTS}

The authors would like to thank the Deanship of scientific research at King Khalid University for supporting the funding of this study, and to the College medicine at King Khalid University for their help in the current study.

EID, R. A.;ZAKI, M. S. A.; AL-SHRAIM,@M.; ELDEEN, M. A.; MASSOUD, E. E. S.; SHA TI, A. A.; KAMAR, S. S. \& HAIDARA, M. A. Silymarin's defensive role against hepatotoxicity induced by amiodaron ein albino rats. Int. J. Morphol., 39(2):407-415, 2021.

RESUMEN:La amiodarona (AMD) es un fuerte medicamento antiarrítmico administrado por vía oral que ha causado hepatotoxicidad en la administración a largo plazo utilizado con frecuencia en todo el mundo. Efectos de mejora de la silimarina (SLM); esta investigación analizó la magnitud del daño al tejido hepático en la DMAE. Dividimos 24 ratas albinas de manera uniforme en cuatro grupos que recibieron dosis diarias por sonda gástrica durante ocho semanas de la siguiente manera; el primer grupo fue designado como grupo control; el segundo grupo recibió SLM; el tercer grupo recibió AMD; y el cuarto grupo recibió AMD en paralelo a SLM. Se prepararon tejidos hepáticos para muestras de suero, microscopía de luz y electrónica y se analiza- ron para biomarcadores (I) enzimas de daño hepático, alanina aminotransferasa (ALT) y aspartato aminotransferasa (AST); (II) estrés oxidativo y antioxidante, malondialdehído (MDA) y superóxido dismutasa (SOD); y (III) marcadores inflamatorios, factor de necrosis tumoral alfa (TNF- $\alpha$ ) e interleucina-6 (IL-6). Los hallazgos mostraron que la DMAE genera cambios histológicos hepáticos que incluyen congestión de los vasos sanguíneos, infiltración leucocítica y vacuolación citoplásmica. Se observó una degeneración ultraestructural de las mitocondrias, aumento del retículo endoplásmico, picnosis nuclear y aumento de gotitas de grasa y lisosomas. Los hallazgos bioquímicos mostraron un aumento en las actividades de ALT y AST del grupo AMD. El grupo de ratas tratadas con AMD y SLM, aumentó las mejoras en histología y ultraestructura, mientras que se redujeron los niveles de ALT y AST. Nuestros hallazgos coincidieron colectivamente en que SLM tiene un impacto protector sobre la hepatotoxicidad de AMD debido a sus propiedades antioxidantes.

PALABRAS CLAVE: Amiodarona; Silimarina; Hígado; Enzimas bioquímicas; Histología, Ultraestructura; Análisis estadístico.

\section{REFERENCES}

Abdel-Moneim, A. M.; Al-Kahtani, M. A.; El-Kersh, M. A. \& Al-Omair, M. A. Free radical-scavenging, anti-inflammatory/anti-fibrotic and hepatoprotective actions of taurine and silymarin against $\mathrm{CCl} 4$ induced rat liver damage. PLoS One, 10(12):e0144509, 2015.

Ahmad, I.; Shukla, S.; Kumar, A.; Singh, B. K.; Kumar, V.; Chauhan, A. K.; Singh, D.; Pandey, H. P. \& Singh, C. Biochemical and molecular mechanisms of $\mathrm{N}$-acetyl cysteine and silymarin-mediated protection against maneb- and paraquat-induced hepatotoxicity in rats. Chem. Biol. Interact., 201(1-3):9-18, 2013.

Bancroft, J. D. \& Gamble, M. Theory and Practice of Histological Techniques. $5^{\text {th }}$ ed. Philadelphia. Churchil-Livingstone, 2002. pp.377694

Bozzola, J. J. \& Russell, L. D. Electron Microscopy. Principles and Techniques or Biologists. $2^{\text {nd }}$ ed. Boston, Jones and Bartlett Publishers, 1999. pp.670.

Castro, N. M. \& Camargo, J. S. Color açãopolicrômica de cortes histológicos. An. Fac. Farm. Odontol Univ. São Paulo, 9:211-5, 1951.

Dawson, B. \& Trapp, R. G. Basic and Clinical Biostatistics. $3^{\text {rd }}$ ed. New York, Lang Medical Books/McGraw-Hill, 2001

Drury, R. A.; Wallington, E. A. \& Cancerson, R. Carlton's Histopathological Techniques. Oxford, Oxford University Press, 1976.

Eid, R. A.; Khalil, M. A.; Alkhateeb, M. A.; Eleawa, S. M.; Zaki, M. S. A.; El-Kott, A. F.; Al-Shraim, M.; El-Sayed, F.; Eldeen, M. A.; Bin-Meferij, M. M.; et al. Exendin- 4 attenuates remodeling in the remote myocardium of rats after an acute myocardial infarction by activating b-arrestin-2, protein phosphatase 2A, and glycogen synthase kinase-3 and inhibiting b-catenin. Cardiovasc. Drugs Ther., 2020. DOI: https:// www.doi.org/10.1007/s10557-020-07006-9

Fonseca, P.; Dias, A.; Gonçalves, H.; Albuquerque, A. \& Gama, V. Acute hepatitis after amiodarone infusion. World J. Clin. Cases, 3(10):900-3, 2015.

Ford, A. C.; Sandborn, W. J.; Khan, K. J.; Hanauer, S. B.; Talley, N. J. \& Moayyedi, P. Efficacy of biological therapies in inflammatory bowel disease: systematic review and meta-analysis. Am. J. Gastroenterol., 106(4):644-59, 2011.

Gonder, J. C. \& Laber, K. A renewed look at laboratory rodent housing and management. ILAR J., 48(1):29-36, 2007. 
Jekarl, D. W.; Lee, S. Y.; Lee, J.; Park, Y. J.; Kim, Y.; Park, J. H.; Wee, J. H. \& Choi, S. P. Procalcitonin as a diagnostic marker and IL-6 as a prognostic marker for sepsis. Diagn. Microbiol. Infect. Dis., 75(4):342$7,2013$.

Joukar, S.; Zarisfi, Z.; Sepehri, G. \& Bashiri, A. Efficacy of Melissa officinalis in suppressing ventricular arrhythmias following ischemiareperfusion of the heart: a comparison with amiodarone. Med. Princ. Pract., 23(4):340-5, 2014.

Karimi, G.; Vahabzadeh, M.; Lari, P.; Rashedinia, M. \& Moshiri, M. "Silymarin", a promising pharmacological agent for treatment of diseases. Iran. J. Basic Med. Sci., 14(4):308-17, 2011.

Lafuente-Lafuente, C.; Alvarez, J. C.; Leenhardt, A.; Mouly, S.; Extramiana, F.; Caulin, C.; Funck-Brentano, C. \& Bergmann, J. F. Amiodarone concentrations in plasma and fat tissue during chronic treatment and related toxicity. Br. J. Clin. Pharmacol., 67(5):511-9, 2009.

Lewis, J. H.; Mullick, F.; Ishak, K. G.; Ranard, R. C.; Ragsdale, B.; Perse, R. M.; Rusnock, E. J.; Wolke, A.; Benjamin, S. B.; Seeff, L. B.; et al. Histopathologic analysis of suspected amiodarone hepatotoxicity. Hum. Pathol., 21(1):59-67, 1990.

Martin 2nd, W. J.; Kachel, D. L.; Vilen, T. \& Natarajan, V. Mechanism of phospholipidosis in amiodarone pulmonary toxicity. J. Pharmacol. Exp. Ther., 251(1):272-8, 1989.

Mata-Santos, H. A.; Dutra, F. F.; Rocha, C. C.; Lino, F. G.; Xavier, F. R.; Chinalia, L. A.; Hossy, B. H.; Castelo-Branco, M. T. L.; Teodoro, A. J.; Paiva, C. N. \& dos Santos Pyrrho, A. Silymarin reduces profibrogenic cytokines and reverses hepatic fibrosis in chronic murine schistosomiasis. Antimicrob. Agents Chemother., 58(4):2076-83, 2014.

Mercer, E. H. \& Birbeck, M. S. C. Electron Microscopy. A Handbook for Biologists. Oxford, Blackwell, 1966.

Mylroie, A. A.; Collins, H.; Umbles, C. \& Kyle, J. Erythrocyte superoxide dismutase activity and other parameters of copper status in rats ingesting lead acetate. Toxicol. Appl. Pharmacol., 82(3):512-20, 1986.

Nasri, H. R.; Joukar, S.; Kheradmand, H.; Poursalehi, H. R. \& Dabiri, S. Coadministration of atorvastatin and amiodarone increases the risk of pulmonary fibrosis in rats. Med. Princ. Pract., 25(2):150-4, 2016.

Nicolescu, A. C.; Comeau, J. L.; Hill, B. C.; Bedard, L. L.; Takahashi, T.; Brien, J. F.; Racz, W. J. \& Massey, T. E. Aryl radical involvement in amiodarone-induced pulmonary toxicity: investigation of protection by spin-trapping nitrones. Toxicol. Appl. Pharmacol., 220(1):60-71, 2007.

Ohkawa, H.; Ohishi, N. \& Yagi, K. Assay for lipid peroxides in animal tissues by thiobarbituric acid reaction. Anal. Biochem., 95(2):351-8, 1979.

Sasu, A.; Herman, H.; Mariasiu, T.; Rosu, M.; Balta, C.; Anghel, N.; Miutescu, E.; Cotoraci, C. \& Hermenean, A. Protective effects of silymarin on epirubicin-induced mucosal barrier injury of the gastrointestinal tract. Drug Chem. Toxicol., 38(4):442-51, 2015.

Schumann, G. \& Klauke, R. New IFCC reference procedures for the determination of catalytic activity concentrations of five enzymes in serum: preliminary upper reference limits obtained in hospitalized subjects. Clin. Chim. Acta, 327(1-2):69-79, 2003.

Shaker, M. E.; Zalata, K. R.; Mehal, W. Z.; Shiha, G. E. \& Ibrahim, T. M. Comparison of imatinib, nilotinib and silymarin in the treatment of carbon tetrachloride-induced hepatic oxidative stress, injury and fibrosis. Toxicol. Appl. Pharmacol., 252(2):165-75, 2011.

Streetz, K. L.; Tacke, F.; Leifeld, L.; Wüstefeld, T.; Graw, A.; Klein, C.; Kamino, K.; Spengler, U.; Kreipe, H.; Kubicka, S.; et al. Interleukin 6/ gp130-dependent pathways are protective during chronic liver diseases. Hepatology, 38(1):218-29, 2003.

Tsai, J. H.; Liu, J. Y.; Wu, T. T.; Ho, P. C.; Huang, C. Y.; Shyu, J. C.; Hsieh, Y. S.; Tsai, C. C. \& Liu, Y. C. Effects of silymarin on the resolution of liver fibrosis induced by carbon tetrachloride in rats. J. Viral Hepat., 15(7):508-14, 2008.

Wojnarová, L.; Kutinová Canová, N.; Farghali, H. \& Kuc`era, T. Sirtuin 1 modulation in rat model of acetaminophen-induced hepatotoxicity. Physiol. Res., 64(Suppl. 4):S477-87, 2015.

\section{Corresponding author: \\ Dr. Refaat A. Eid \\ Department of Pathology \\ College of Medicine \\ King Khalid University \\ Abha \\ SAUDI ARABIA}

Email: refaat_eid@yahoo.com

ORCID: 0000-0001-5633-9562

Received: $28-08-2020$

Accepted: $30-11-2020$ 